\title{
Some Problems in the Explanation of Interest Rates
}

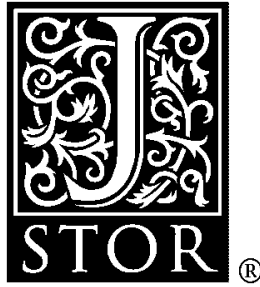

\section{J. Tinbergen}

The Quarterly Journal of Economics, Vol. 61, No. 3. (May, 1947), pp. 397-438.

Stable URL:

http://links.jstor.org/sici?sici=0033-5533\%28194705\%2961\%3A3\%3C397\%3ASPITEO\%3E2.0.CO\%3B2-8

The Quarterly Journal of Economics is currently published by The MIT Press.

Your use of the JSTOR archive indicates your acceptance of JSTOR's Terms and Conditions of Use, available at

http://www.jstor.org/about/terms.html. JSTOR's Terms and Conditions of Use provides, in part, that unless you have obtained prior permission, you may not download an entire issue of a journal or multiple copies of articles, and you may use content in the JSTOR archive only for your personal, non-commercial use.

Please contact the publisher regarding any further use of this work. Publisher contact information may be obtained at http://www.jstor.org/journals/mitpress.html.

Each copy of any part of a JSTOR transmission must contain the same copyright notice that appears on the screen or printed page of such transmission.

JSTOR is an independent not-for-profit organization dedicated to and preserving a digital archive of scholarly journals. For more information regarding JSTOR, please contact support@jstor.org. 


\section{SOME PROBLEMS \\ IN THE EXPLANATION OF INTEREST RATES ${ }^{1}$}

\section{SUMMARY}

I. Scope of the paper, 397. - The credit market, 397. - Model A, 400. - Model B, 403. - Model C, 403. - Model D, 404. - Income lags, 405. Ex-ante and ex-post concepts, 406. - The determinants of active savings, 409. - The determinants of depreciation allowances, 411. - The determinants of credit creation, 412. - Purchase and sale of securities, 412. - The demand side: new investment, 413; reinvestment, 414; cash holdings, 415. - Length of the elementary period, 417. - Keynes on the classical authors: savings, 418; net flow and gross flow, 420. - II. The markets for long and short credits, 423. - The demand for short credits, 424. - The supply of short credits, 425. - The demand for long credits, 426. - The supply of long credits, 426. - The cyclical behavior of interest rates, 427. - Interest rates in the principal countries: differences in level, 432; characteristics of movements, 432. - Econometric analysis, 433. - Interest rates and the price level, 434. - Physical determinants of the interest rate, 436. - Explaining the cyclical movement of interest rates, 437 .

\section{I}

1. The present paper embodies a digest of some recent literature on the theory of interest rates, with the special purpose of using that theory for econometric analysis. The final purpose of that analysis may be formulated as the explanation of the differences between: $(a)$ interest rates in different countries at one time; (b) various types of interest rates in the same country and at the same time; and $(c)$ the development in time of these interest rates. All econometric analysis has to start from a theoretical scheme of the subject in question; and the object of such a theoretical scheme is to indicate the "determinants" or "data" of the rates of interest and the functional relationship between these rates and their determinants. These determinants or data must be entities outside the market complex on which the interest rate is formed.

2. The market complex in question is the credit market. ${ }^{2}$

1. I am much indebted to Prof. Dennis H. Robertson for valuable comments on the first draft of this article.

2. I prefer in this respect the standpoint taken by Ohlin, Alternative Theories of the Rate of Interest, Economic Journal XLVII (1937), p. 423, Haberler, Prosperity and Depression, 3d edition, 1941, and Lerner, Alternative Formulations of the Theory of Interest, Economic Journal, XLVIII (1938), p. 211, to that taken by Keynes, although I consider the difference unimportant. 
For an explanation of interest rates we have to analyze demand for and supply of credit. The element of this market, the single credit contract, has two dimensions at least: a certain amount is lent for a certain time period and the total of all credits outstanding at a given point of time is a so-called "ensemble renouvelé," like the human population. In order exactly to describe this "population" we have to use rather complicated symbols. ${ }^{3}$ We shall indicate by ${ }_{T} K_{t}$ the total amount of new credits started during the elementary period $t$ and expiring at $T ;{ }_{T} K_{t}^{o}$ the total amount of outstanding credits at the beginning of the elementary period $t$ and expiring at $T ; K_{t}^{n}$ the total amount of new credits started during $t$, irrespective of their period of expiration; hence $K_{t}^{n}$ is obtained by adding up all ${ }_{T} K_{t}^{n}$ 's for various values of $T$ :

$$
K_{t}^{n}=\Sigma^{T}{ }_{T} K_{t}^{n} \text {. }
$$

Similarly, the total amount of credits outstanding at $t$

$$
K_{t}^{o}=\Sigma^{T}{ }_{T} K_{t}^{o} \text {. }
$$

Indicating by $K_{t}^{E}$ the total amount of credits expiring during $t$ - which, by the way, equals the sum $\Sigma_{T} K_{t}^{n}$ taken over all values of $T<t$ - we have the following calculation for the amount of credit outstanding at the end of period $t$ :

$$
K_{t+1}^{o}=K_{t}^{o}+K_{t}^{n}-K_{t}^{E}
$$

which is quite analogous to the calculation of a population at December 31 from the figure at January 1, plus the number of births, minus the number of deaths.

I could conceive of another description of the market complex that is relevant for the explanation of interest rates, viz. by taking the market complex for all elements of wealth, including e.g. the stock market which, strictly speaking, is not a credit market in the narrower sense and nevertheless exerts considerable influence on the interest rates; in fact, the yield on stocks may be said to represent one of the interest rates. I shall not, however, follow this line of attack.

3. The system of notation followed is based on the following rules. The right-hand index at the bottom indicates, for flows, the elementary time period and, for stocks, the time point to which it relates. The beginning of an elementary time period is indicated by the same number as that period and hence the end point by the next higher number. The left-hand indices at the bottom are used to indicate sorts of commodities (consumption goods: $C$; investment goods in general: $I$; investment goods for reinvestment: $R$; for new investment $N$, etc.), or sorts of eredits (long: $L$, short: $S$ ) or the time of expiration of a credit: $T$. Left-hand top indices are used for the denotation of sorts of households spending (not those receiving) a given type of money amount (family households: 1 ; firms: 2 ; banks: 3 ; all households on the demand 
The period of expiration of a credit need not be a fixed one; it may depend on several, yet unknown, factors. It may, for example, depend on the market conditions prevailing at a later time, as in the case of mortgage bonds, which may be bought back by the issuers at a time point at their own convenience. In such a case, the individual credit can only roughly be classified, and the symbol ${ }_{T} K_{t}^{n}$ is indeterminate; $K_{t}^{n}$, however, remains determinate. The same situation exists in the case of a bond which changes hands. Let a four per cent bond be issued by firm $\mathrm{A}$ and be redeemable after forty years, the subscriber being Mr. B. Provisionally a credit for forty years is yielded by B to A. If, however, after five years, Mr. B sells his bond to Mr. C at a price of 80 , the credit of $\mathrm{B}$ to $\mathrm{A}$ expires and is replaced by a new credit of $\mathrm{C}$ to $\mathrm{A}$, with an interest rate equal to the yield at that moment which will be somewhere between four and five per cent. ${ }^{4}$ By $K_{t}^{N}$ we shall understand the increase in credit outstanding, i.e.

$$
K_{t}^{N}=K_{t+1}^{o}-K_{t}^{o}=K_{t}^{n}-K_{t}^{E}
$$

The use of this concept will appear in section 19, where we shall discuss the "stock-and-flow antithesis."

Demand for and supply of credits relate to the new credits started $K_{t}^{n}$, including, therefore, inter alia sales of old bonds on the stock exchange.

3. The essential feature of a credit to the debtor is disposal side of a market: $D$, on the supply side: $S$, etc.). The right-hand top indices are reserved for various indications, as e.g. sorts of income (interest: $I$, rent: $R$, etc.), outstanding vs. new credits $(O, N, n$, respectively; see below), etc. Summarizing:

Left-hand top: spending households

$\begin{array}{ll}\text { Family } & 1 \\ \text { Firms } & 2 \\ \text { Banks } & 3 \\ \text { Demand side } & D \\ \text { Supply side } & S\end{array}$

Left-hand bottom: goods

Reinvestment $R$

New investment $N$

Long credits $L$

Short credits $\quad S$

Time of exp. $\quad T$ omitted.

For simplicity's sake, if no confusion threatens, sometimes indices are
Right-hand top: mixed indications Credits outstanding $O$

New credits (gross) $n$

Credits expiring $\quad E$

New credits (net) $\quad N$

Interest income

Right-hand bottom:
Time $n$
$E$
$N$
$I$

$t$

4. At the same time, B suffers a capital loss, which means a transformation of part of his credit to $\mathrm{A}$ into a pure gift. 
of means of payment or money; hence the close relations between the demand for and supply of credit and of cash. A credit may be granted (i) by transfer of existing means of payment from one subject to another, and (ii) by the creation of new means of payment. This creation is supposed to be the special function of the banking system. In order to get, for a given model of the national economy, a complete survey of all credit transactions, it is convenient to start with a survey of all money transactions and then to distinguish between two sorts of transactions: credit and "other" transactions. The "other" transactions may be characterized, from the viewpoint of the recipient, as receipts from present or past activity and from the viewpoint of the payer as payments "out of his own means."

The models we are to consider will be very much simplified models of a national economy. Throughout this paper we shall restrict ourselves to a closed national economy; we shall not consider the implications of international transactions, since this would involve us in too many new problems. In all our models we shall distinguish between only three sorts of households: (1) family households, (2) firms (excluding banks, but including public authorities), and (3) banks, to be indicated, where necessary, by top indices 1,2 , and 3 at left. We assume vertical integration throughout the system, i.e. we consider all business firms as a unit. For the same reason we abstract from the original supplier of and the last demander for credit we shall consider. Of course there is room, in more detailed studies, for the introduction of the intermediary markets as well. The only remaining function of the banks in this picture is the (positive or negative) creation of credit.

Looking first at that part of the credit market that consists of the transfer of existing means of payment, we may therefore restrict ourselves to the first two types of households. In each category there will be households with a net supply of and households with a net demand for credits. It is impossible to say beforehand whether a given household belongs to the one or the other type; that may depend on the rate of interest itself. This does not matter very much, since the algebraic sign of the expression "demand for minus supply of credit" will automatically indicate whether there is a net demand or a net supply.

4. In our first and simplest model, "model $\mathrm{A}$," we assume 
inter alia that (i) all business profits are paid out to stockholders (i.e. to family households); (ii) production is carried on without the help of durable means of production, implying that there are no depreciation charges; (iii) there are no financial transactions (i.e. no dealing in "old" securities, only the floating of "new" capital); (iv) there is no lag between income generated and income paid out.

The system of transactions of family households during the elementary period $t$ then consists of:

Payments

Consumption Expenditure

"Active" Savings (or savings

handed over)

Redemptions reinvested

$C_{t}$
$S_{t}$
$K_{t}^{E}$

Receipts

$\begin{array}{ll}\text { Incomes } & Y_{t} \\ \text { Credits redeemed } & K_{t}^{E}\end{array}$

The introduction, on both sides, of the term $K_{t}^{E}$ is a question of definition of $S_{t}$ only; in practice it is impossible to distinguish between the reinvestment of redemptions and the investment of new savings; "net" savings handed over will be considered simply as the balance between gross savings handed over and redemption receipts.

Indicating the cash holdings at the beginning of the period by ${ }^{1} M_{t}$ and those at the end by ${ }^{1} M_{t+1}$, the following connection exists between these items:

$$
Y_{t}-C_{t}-S_{t}={ }^{1} M_{t+1}-{ }^{1} M_{t}
$$

This equation is equivalent to a definition of "active savings." By $S_{t}$ we understand that part of income $Y_{t}$ which is neither consumed $\left(C_{t}\right)$ nor hoarded $\left({ }^{1} M_{t+1}-{ }^{1} M_{t}\right)$; hence:

$$
S_{t}=Y_{t}-C_{t}-\left({ }^{1} M_{t+1}-{ }^{1} M_{t}\right) \text {, }
$$

which is identical with $(4,1)$.

This definition requires two comments. First it must be noted that by hoarding we simply mean the increase in cash holding; this hoarding may be distinguished into intended and unintencled hoarding; these notions will be discussed later (sections 9 and 11). Apart from these two types of "family hoarding," there may exist "business hoarding." Further, our definition of active savings is exclusive of hoarding; this implies a difference from both the Keynesian and the Robertsonian definitions of savings: Keynes includes all hoarding (in our sense) in his savings, whereas Robertson includes all intended (family) hoarding. 
Savings may, for a number of households, be negative. This simply means that their contribution to $S_{t}$ is a negative one; $S_{t}$ taken for all households represents "net" active savings also in this sense. Of the transactions enumerated the term $S_{t}$ and the double term $K_{t}^{E}$ on both sides are the credit transactions, relevant for our analysis. As a rule, $S_{t}$ will be positive and represent one of the supply items of the market equation.

5. The system of transactions of business firms consists of:

Payments

Income payments

Investments

Redemption of credits
Receipts

$Y_{t} \quad$ Sales of consumers' goods $C_{t}$ $I_{t} \quad$ Sales of investment goods $I_{t}$ $K_{t}^{E} \quad$ New credits taken
$I_{t}$

Indicating by ${ }^{2} M_{t}$ and ${ }^{2} M_{t+1}$ the cash holdings at the beginning and the end of period $t$, the relation holds:

$$
Y_{t}+I_{t}+K_{t}^{E}+{ }^{2} M_{t+1}=C_{t}+I_{t}+K_{t}^{n}+{ }^{2} M_{t} .
$$

This may also be written as:

$$
K_{t}^{n}=K_{t}^{E}+I_{l}+\left(Y_{t}-C_{t}-I_{t}\right)+{ }^{2} M_{t+1}-{ }^{2} M_{t} .
$$

If there is no lag between income generated $C_{t}+I_{t}$ and income paid out $Y_{t}$, and hence

$(5,2)$ becomes:

$$
Y_{t}=C_{t}+I_{t}
$$

$$
K_{t}^{n}=K_{t}^{E}+I_{t}+{ }^{2} M_{t+1}-{ }^{2} M_{t}
$$

telling us that new credits are, then, needed for three different ends:

(a) to replace credits redeemed;

(b) to finance new investments; and

(c) to finance a desired increase in cash holdings.

As the non-credit items in the system of transactions we consider $Y_{t}, C_{t}$ and $I_{t}$ which, in our case, just cancel out. This is not so in the case of a lag between income produced and income paid out.

For the group of business firms as a whole, $K_{t}^{n}$ as a rule will be positive and therefore represent a net demand for new credits.

Considering now the credit-market as a whole, we shall find that the net supply of credits by the family households $S_{t}$ need not always be equal to the net demand for credits by business units ${ }^{D} K_{t}^{n}$. The gap, if any, may be filled by the banking system in the form of positive or negative creation of credit $M_{t}^{N}$. Hence the equation expressing the balance between supply of and demand 
for new credits will run:

$$
K_{t_{\mathrm{o}}}^{E}+S_{t}+M_{t}^{N}={ }^{D} K_{t}^{n}
$$

which may be specified with the aid of equation $(5,4)$ :

$$
K_{t}^{E}+S_{t}+M_{t}^{N}=K_{t}^{E}+I_{t}+{ }^{2} M_{t+1}-{ }^{2} M_{t}
$$

where the terms $K_{t}^{E}$ may be left out altogether.

6. We shall now consider a number of complications of our model that will bring it nearer to reality. In "model B" let part of the national income take the form of undistributed profits ${ }^{2} Y_{t}$; family incomes will then be:

and family savings:

$$
{ }^{1} Y_{t}=C_{t}+I_{t}-{ }^{2} Y_{t}
$$

$$
{ }^{1} S_{t}={ }^{1} Y_{t}-C_{t}-\left({ }^{1} M_{t+1}-{ }^{1} M_{t}\right)
$$

${ }^{2} Y_{t}$ may be said to represent business savings and equation $(5,6)$ becomes:

$$
{ }^{1} S_{t}+M_{t}^{N}=\left(I_{t}-{ }^{2} Y_{t}\right)+\left({ }^{2} M_{t+1}-{ }^{2} M_{t}\right)
$$

The term $I_{t}-{ }^{2} Y_{t}$ in the right-hand member now stands for that part of investment which is not financed out of business savings. Of course we might also bring over ${ }^{2} Y_{t}$ to the left-hand side of the equation:

$$
{ }^{1} S_{t}+{ }^{2} Y_{t}+M_{t}^{N}=I_{t}+\left({ }^{2} M_{t+1}-{ }^{2} M_{t}\right)
$$

where ${ }^{1} S_{t}+{ }^{2} Y_{t}$ again stands for total active (family plus business) savings.

Similar considerations may be applied for the case (model B') where part of family savings is invested directly, say in new house building. Indicating this type of investment by ${ }^{1} I_{t}$ as distinct from business investment ${ }^{2} I_{t}$, equation $(5,6)$ turns into:

$$
S_{t}-{ }^{1} I_{t}+M_{t}^{N}={ }^{2} I_{t}+{ }^{2} M_{t+1}-{ }^{2} M_{t}
$$

where $S_{t}-{ }^{1} I_{t}$ now represents active savings as far as not invested directly. Also here the equation might be written in the form

$$
S_{t}+M_{t}^{N}={ }^{2} I_{t}+{ }^{1} I_{t}+{ }^{2} M_{t+1}-{ }^{2} M_{t}
$$

where $I_{t}$ appears now decomposed into two components.

7. A more important step consists in the introduction ("model C") of depreciation charges, as a consequence of the use of durable means of production.

It is natural, in this case, also to decompose $I_{t}$ into two components: reinvestments ${ }_{R} I_{t}$ and new investments, ${ }_{N} I_{t}$. Income 
$Y_{t}$ now no longer equals $C_{t}+I_{t}$, but:

$$
Y_{t}=C_{t}+I_{t}-N_{t}=C_{t}+{ }_{R} I_{t}+{ }_{N} I_{t}-N_{t}
$$

where $N_{t}$ represents depreciation charges. Equation $(5,2)$ now runs:

$$
K_{t}^{n}=K_{t}^{E}+{ }_{N} I_{t}+{ }_{R} I_{t}-N_{t}+{ }^{2} M_{t+1}-{ }^{2} M_{t}
$$

and the market equation $(5,6)$ for new credits becomes:

$$
S_{t}+N_{t}+M_{t}^{N}={ }_{N} I_{t}+{ }_{R} I_{t}+\left({ }^{2} M_{t+1}-{ }^{2} M_{t}\right)
$$

Here there appear three sources of supply: net savings, depreciation charges and credit creation, and three origins of demand; new investments, re-investments and increased cash holdings.

8. One further complication worth considering is the introduction into the picture ("model D") of financial transactions, i.e. purchases and sales of "old" securities. Since it is difficult to distinguish between purchases of old and of freshly floated securities, it seems logical to speak of purchases of securities ${ }^{D} E_{t}$ only, and to indicate by ${ }^{1} S_{t}$, all other forms of active savings. In the same way, let us indicate by ${ }^{I} E_{t}$ new issues of securities, and by $I_{t}{ }^{\prime}$ all other credits taken for investment purposes. If, finally, sales of old securities are written as ${ }^{s} E_{t}$, the family budget runs:

Payments

Consumption expenditure $C_{t} \quad$ Income

Purchases of securities

${ }^{D} E_{t} \quad$ Sales of securities

$Y_{t}$

Other active savings

Receipts

Increase in cash holdings ${ }^{1} M_{t+1}-{ }^{1} M_{t}$

whereas the business budget is:

Income payments

$Y_{t}$

$I_{t} \quad$ Sales of investment goods

Sales of consumers' goods $C_{t}$ Investments

Capital issues ${ }^{I_{t}} E_{t}$

All other credits taken $\quad K_{t}^{\prime}$

Now the market equation for credits, including financial transactions, takes the form:

$$
{ }^{1} S_{t}{ }^{+}+{ }^{D} E_{t}+M_{t}^{N}=I_{t}{ }^{\prime}+{ }^{I} E_{t}+{ }^{S} E_{t}+{ }^{2} M_{t+1}-{ }^{2} M_{t}
$$

We may, if we prefer, combine the various more complicated models so far discussed into one single combined model. For this the market equation would run:

$$
{ }^{1} S_{t}{ }^{\prime}+{ }^{D} E_{t}+{ }^{2} Y_{t}+N_{t}-{ }^{1} I_{t}+M_{t}^{N}={ }_{N}^{2} I_{t}{ }^{\prime}+{ }^{I} E_{t}+{ }^{S} E_{t}+{ }_{R}^{2} I_{t}+\left({ }^{2} M_{t+1}-{ }^{2} M_{t}\right)
$$


where the meaning of the new symbols will be clear from the preceding ones.

9. In the foregoing models it was assumed that there exists no lag between income generated $C_{t}+I_{t}$ and income paid out $Y_{t}$. In reality however, there is such a lag; it takes some time for consumption and investment expenditures $C_{t}$ and $I_{t}$ to reach the ultimate producers. First, production takes place in various stages, and in the raw material stages, for example, the reaction of an increase in expenditures may be felt several months later than in the first stage, although this may be compensated by anticipating purchases of raw materials by the manufacturing stages. And second, some types of income, in particular dividends, are paid out several months after they are earned. Hence we have in the simplest case, where we assume that the lag is uniform for all industries:

$$
Y_{t}=C_{t-\theta}+I_{t-\theta} .
$$

This implies that, in the case of model $A$, equation $(5,2)$ cannot simply be transformed into equation $(5,4)$ by omitting $Y_{t}-C_{t}-I_{t}$; instead we obtain:

$$
K_{t}^{n}+\left(Y_{t+\theta}-Y_{t}\right)=K_{t}^{E}+I_{t}+\left({ }^{2} M_{t+1}-{ }^{2} M_{t}\right)
$$

to be interpreted in the following way: part of the credits needed can now be supplied by the "unintentional business hoarding" $Y_{t+\theta}-Y_{t}$, accruing when at a period $t$ income earned - which equals $Y_{t+\theta}$ - is higher than income paid out; or more credit is needed during a period when income earned is lower than income paid out. Similar changes can be made in the other models.

The lag just discussed works out in exactly the same way as the lag considered by Robertson and introduced by him as the lag between earned income and "disposable income"; his "disposable income" takes the place of our "income paid out." It is not quite clear, however, whether Robertson includes, in his lag, the elements just mentioned.

There is another very important lag in the relations to be studied - the "psychological lag" between changes in income paid out and the corresponding changes in consumption expenditures. This lag does not influence our definition of savings $(4,1)$, however, but only the way in which $C_{t}$, and hence also $S_{t}{ }^{\prime}$, depend on income. In other words, it is a question of the determinants of $S_{t}$ rather than of the definition. To this question we now turn. 
10. In the preceding sections we have only specified the demand for a supply of credits; we have not yet gone into the question what factors determine them and what the relation between demand and supply and their determinants is. In the language of the ordinary market theory, we now want to describe the demand function, i.e. the functional relationship between (i) amount demanded and (ii) the rate of interest and the other "demand factors," which may also be named "data" or "determinants." Similarly for the supply function. It has become customary, particularly in the theory of interest, to replace this terminology by the well-known ex-ante and ex-post terminology. The subject of the present section may therefore also be formulated as follows: have we to interpret the symbols introduced in the preceding sections as ex-ante or ex-post concepts? Since it seems to me that several formulations of this terminology by the Swedish school are rather unsatisfactory, we may go into these questions at some detail now.

There is no difficulty about the meaning of ex-post concepts: they represent the realized values of the variables in question; and there is complete analogy between the market theory and the Swedish terminology: the realized values of "quantity demanded" and "quantity supplied" are equal. These realized values are, in essence, numbers and must be well distinguished from the demand and supply functions or schedules, a distinction which frequently is not made with sufficient emphasis. Its neglect has often led to unclear formulations. It is exactly the same question with the Swedish terminology. A good deal of clarification has been obtained by Ohlin's statement ${ }^{5}$ that expectations or ex-ante entities are to be seen as schedules; in fact, they are nothing but the demand and supply schedules. This implies, first of all, that they depend on the yet unknown value of - in the case of the credit market the rate of interest $m$. It also implies that the following two types of statement, very frequently used, are meaningless: (a) "ex-ante savings are unequal to ex-post savings"; and (b) "ex-ante savings are unequal to ex-ante investment." Statement (a) would mean that a schedule is compared with one special value of the dependent variable; can one say that the function $f(x)$ is unequal to the particular value that function assumes for $x=a$;

5. Cf. B. Ohlin, Alternative Theories of the Rate of Interest, Economic Journal 47 (1937), p. 423. 
can one say, in other words, that $f(x) \neq f(a)$ ? Evidently not. Statement (b) implies that one schedule is unequal to another schedule, or that a function of some independent variables is unequal to another function of some other independent variables, which also has no meaning.

The confusion is, of course, due to the existence of a second meaning of the concept of ex-ante variables, viz. one particular value of the schedule. This particular value can only be obtained by assuming for the independent variables in the schedule some definite values. Taking, for example, some definite number for the interest rate $m$ and for the other determinants, we get a definite value for savings ex-ante or anticipated savings. These values of both the independent and the dependent variables may be values that, with some right, are to be considered as the most probable values. But this second meaning of "expectations" must be carefully distinguished from the schedule meaning.

As already observed, the schedules will depend on other variables besides the rate of interest $m_{t}$. Some of them may be fixed beforehand; for example, credits granted in earlier periods, building plans, etc. Others, however, may be yet unknown variables; for example, income $Y$ in the same period. In such cases the value of savings depends on more than one yet undetermined variable; it will itself only be determined at the moment $m_{t}$ and $Y_{t}$ will be determined by the trial-and-error process that leads to the market price $m_{t}$ and, perhaps but not necessarily, simultaneously to $Y_{t}$.

The process of the formation of $m_{t}$ and that of the formation of $Y_{t}$ need not, in fact, be simultaneous. It is possible that $m_{t}$ may be obtained by decisions based on some provisional value assumed for $Y_{t}$ by the market parties - they may assume it to be equal to the realized value $Y_{t-1}$ in the preceding period and that, at the same time, $Y_{t}$ is based on some provisional value for $m_{t}$, may be $m_{t-1}$. As already stated, however, we also may assume that both variables $m_{t}$ and $Y_{t}$ are formed simultaneously from the other data in the determining functions. The theory thus obtained is more approximative, is of a "coarser" type than the preceding one; the supposed adaptation or "trial-and-error" process by which the values $m_{t}$ and $Y_{t}$ are formed is neglected and passed over. It is the usual static method in economic theory that proceeds this way; it may be used for the general equilibrium of the whole economy as well as for partial equilibria. 
But also the "finer" theory mentioned above, where $m_{t}$ is assumed to be determined by the interaction of demand and supply - although not $Y_{t}$ but $Y_{t-1}$ appears as one of the determinants - does not consider the adaptation process in full detail. It is only in a complete dynamic theory that this happens. In such a theory an $m_{t}$ found by trial and error does not fall from the air. The trials and errors themselves are described.

A simple example for a commodity market is the following. Let the quantity demanded at period $t$ be $x_{t}$; it may depend on income $Y_{t-1}$, in the previous period, and the price $p_{t}$. Let the quantity supplied be $y_{t}$; it may depend on $p_{t}$ and some other factor $a_{t-1}$. Now let $p_{t}$ be announced at the beginning of period $t$; then, of course, there is no guarantee that $x_{t}=y_{i}$; in fact $x_{t}$ will as a rule be $\neq y_{t}$. For a market where there exists, at every moment, a stock of unsold goods, this is no difficulty at all. We simply have that the stock $w_{t+1}$ at the end of period $t$ depends on the stock $w_{t}$ at the beginning of the period by the equation $w_{t+1}=w_{t}+y_{t}-x_{t}$ and, as a rule, the value of the "announced price" $p_{t+1}$ will depend on $w_{t+1}: p_{t+1}=f\left(w_{t+1}\right)$.

In such a theory, where all successive steps are described separately, there is no variable that is dependent on a yet unknown value of another variable. Insofar as $p_{t}$ in the course of some time approaches a certain limit, this limit is comparable to the outcome of the trial-and-error process in the "coarser" theories.

Only in such a completely dynamic analysis can all concepts be made exact. All other types of analysis raise the following difficulty. If the demand schedule, for example, depends, inter alia, on the anticipated value, say of $Y_{t}$, then at the beginning of the trial-and-error process this value may be another than during or towards the end of the process when it approaches the ex-post value of $Y_{t}$. Now $m_{t}$ is the product of this process; on what anticipated value of $Y_{t}$ does it depend? Does it depend on the anticipated value of $Y_{t}$ at the beginning of the period $t$, which more or less rightly may be considered as "the" ex-ante value of $Y_{t}$, or does it depend on the "ex-post" value? This difficulty only fails to arise when we consider the successive steps of the adaptation process.

There is not one ex-ante value (in the second sense) of a given variable; there is a whole series, depending on the time point to which the expectation relates; and they successively approach the 
ex-post value. For small intervals, therefore, the difference between ex-ante and ex-post values is not large. Myrdal ${ }^{6}$ however, is right in contending that by making the intervals smaller the difference cannot be made to vanish altogether. What matters, however, is on what determinants the expected values or the schedules are based. And this leads us back to our main subject.

11. We start our discussion of the determinants by considering the determinants of active savings $S_{t}$. The chief determinant is certainly the size and distribution of the national income $Y_{t}$; we need not add very much to what Keynes and others have taught us on this subject. ${ }^{7}$ One aspect, however, deserves a closer examination - the question of the psychological lag that may exist between a change in income and a corresponding change in savings. An increase in income does not immediately lead to a change in consumption or saving habits; and the possibility exists that savings as well as consumption expenditure lag behind incomes. The simplest case is present if this lag is not a distributed, but a simple one; i.e. that $S_{t}=f\left(Y_{t-\eta}\right)$, where $\eta$ is the lag. Assuming for a moment that consumption expenditure $C_{t}$ also depends on $Y_{t-\eta}$, we find that during the elementary period $t$ the total amount handed over to others, viz. $S_{t}+C_{t}$, is also a function of $Y_{t-\eta}$. This amount may or may not be equal to $Y_{t-\eta}$. If it equals $Y_{t-\eta}$, we shall say that there is no intentional hoarding; if it does not equal $Y_{t-\eta}$, we shall call the residual intentional (family) hoarding ${ }^{1} H_{t}$; hence

$$
{ }^{1} H_{t}=Y_{t-\eta}-C_{t}\left(Y_{t-\eta}\right)-S_{t}\left(Y_{t-\eta}\right) .
$$

Apart from intentional hoarding there will appear, as a consequence of the lag $\eta$, an amount of unintentional (family) hoarding:

$$
{ }^{1} H_{t}{ }^{\prime}=Y_{t}-Y_{t-\eta}
$$

which does not occur when $\eta=0$.

The lag we now discuss is not of a technical nature. In some respects, however, a technical lag, due to the organization of banking, will work out in a similar way. In a sense one might say that income $Y_{t}$ only becomes "disposable" (namely, in the imagination of the subject) at the period $t+\eta$ and is then distributed

6. G. Myrdal, Monetary Equilibrium, London, 1939, p. 61.

7. E. A. Radice (Savings in Great Britain, 1922-1935, Oxford, 1939) has shown that business savings also are intimately connected with income, i.e. profits. 
between consumption, savings-handed-over and intentional hoarding. The income difference $Y_{t}-Y_{t-\eta}$ accrued in the meantime represents unintentional hoarding; in the case of the psychological lag this hoarding is located in the cash of the income earner; in the case of a technical lag it will take place in the cash of some business firm, or perhaps of a bank.

It is possible to define our types of hoarding also in the case of a distributed lag between $Y$ and $S$; it would take us too far afield, however, to go into this matter.

Apart from the question of the lag, there is that of the shape of the functional relation $f$ between $S_{t}$ and $Y_{t-\eta}$. This relation may be called, following Keynes to some extent, the propensityto-save function. One of the simplest cases possible is that of a linear function:

$$
S_{t}=\sigma_{0}+\sigma_{1} Y_{t-\eta}
$$

where $\sigma_{0}$ and $\sigma_{1}$ are constants. Assuming this shape does not, as is frequently thought, imply proportionality between income and savings; proportionality would require $\sigma_{0}$ to be zero. The rather meagre statistical material at our disposal is not violated very much if we take $(11,3)$ as the propensity function; although some authors ${ }^{8}$ suggest a constant elasticity (i.e. exponential) function. The advantage of formula $(11,3)$ is that $\sigma_{1}$ at once represents the marginal propensity to save, i.e. the increase in savings corresponding with a (small) unit increase in income.

A more complicated representation of the propensity function could take account of a possible and probable difference between long-term and short-term marginal propensities; this would be possible if we put

$$
S_{t}{ }^{\prime}=\sigma_{0}+\sigma_{1} Y_{t-\eta}+\sigma_{2} \bar{Y}_{t-\eta}
$$

where $\bar{Y}_{t-\eta}$ is an average of previous $Y$-figures, say those prevailing in the ten-year period before $t-\eta$.

Apart from this possibility, there is the one that $\sigma_{0}$ and $\sigma_{1}$ are not exact constants, but themselves dependent on other variables; in fact $(11,4)$ is a special case of this state of affairs. There is not very much known about all this; as a curiosity I mention King's figures on incomes and expenditures of the various classes

8. E. Gilboy, Review of Economic Statistics, 1939. 
of society in the seventeenth century, ${ }^{9}$ from which a propensity to save can be deduced not very different from the present figure.

Savings may also depend on other variables than income, the second variable to be thought of being, of course, the rate of interest. We need not repeat the well-known discussions on this topic and will not encounter much opposition when stating that a very clear dependency of total savings on the rate of interest has never been demonstrated: positive and negative influences seem to balance pretty well. It is quite another question that some particular types of saving do depend on the rates of interest connected with these types; this is a question of substitution elasticity rather than total elasticity.

It goes without saying that there are many other factors that influence savings, such as the opportunities offered, the general level of thriftiness of a population or of an epoch; so very little exact knowledge of them can be presented, however, that we abstain from discussing them here.

12. We proceed to a discussion of the determinants of our next supply item, depreciation allowances. An important general remark about this item is that it is very insensitive to cyclic changes. This is a consequence of its depending on the investments made during a long period - in fact, all investments not yet written off at the time period in consideration. Another reason why there are no pronounced cyclical fluctuations in depreciation allowances may be the rather conventional way of their calculation.

Their long-run movements will depend on the general growth in the value of production and the changes in capitalization and in durability of capital goods. An increasing amount of capital per unit of product will require, other things being equal, an increase in depreciation allowances per unit of product. An increase in the durability of capital goods would cause a fall in depreciation allowances. Colin Clark states that there is such an increase in depreciation charges that we must assume a considerable decrease in the durability of capital goods for the last few decades. ${ }^{1}$

9. Cf. Colin Clark, National Income and Outlay, p. 212. Since this text was written, important contributions to our knowledge on this subject have been published, i.a. by Woytinski, Bean and Klein.

1. C. Clark, National Income and Outlay, London 1937, p. 184. 
13. The determinants of credit creation are to be sought in the sphere of banking policy. For long periods, the changes in the central bank's gold stock will have been outstanding among these determinants. This is affirmed by the figures given by Warren and Pearson, showing a close parallelism - in long-run movements - between gold stock and total money in circulation and between the long waves of the gold stock and those of the price level, already pointed to by Cassel. This parallelism ceased to exist, however, after 1914. Since then, the newer ideas on banking policy as well as the necessities of warfare have given to credit creation a still more exogenous character.

Also in the short run, the fluctuations often diverge. Many other factors intervene; as one of the most evident and most important examples, we again quote the financing of wars and the provisions in periods of trade crisis. The factors then governing the creation of credit are often of an incidental character, and a general description would be very difficult.

The rate of interest itself also exerts an important influence, particularly on that part of credit creation due to commercial banks. This seems to be well illustrated by the results of some correlation calculations presented in my investigation on American business cycles between 1919 and 1932. ${ }^{2}$ There it was found that both the "supply of deposits" and the "demand for short claims" by commercial banks showed a clear dependence on the shortterm interest rate. ${ }^{3}$

For the credit creation by central banks the causal connection - in the short run, at least - just works the other way round: it is the discount rate that is determined autonomically by these banks, and the amount of credit created is determined by the demand for it corresponding with the discount rate.

14. The purchases of securities, a further supply item in the credit market, as well as the sales of "old" securities, will first of all depend on their price level, which, in connection with their nominal yield, determines their real yield, which is nothing but one or another type of interest rate. Important determinants will be the expected price movements and, in the case of stocks, the

2. J. Tinbergen, Business Cycles in the United States of America, 1919-1932)(Statistical Testing of Business Cycle Theories, II), League of Nations, Geneva, 1939.

3. A fuller discussion of the exact meaning of these results is presented in section 24 below. 
expected dividend. Expected dividends are often based on the last-known dividends, but insiders will know more about the actual state of affairs and outsiders will try to judge it from the general course of business. As to the anticipated prices, two ways of forming a judgment must be clearly distinguished. Experts will base their judgment as much as possible on objective criteria, leading them to some level of the price they consider appropriate, and they will assume that sooner or later this level will be realized. They will base their speculations on this type of consideration. The "great public," when coming into the market, will, however, often follow another way of speculating. They will extrapolate past movements more or less automatically and will be impressed by price gains made some time before. Their purchases will, after having passed a certain level, lead to "booms" of a rather dangerous character, where prices lose contact with reality, and the reaction may be a crisis. A statistical illustration of this type of reaction is found in the League of Nations investigation already referred to (cf. Section 4, 8: "The share price equation," page 106).

15. Turning to the demand side, we first discuss the determinants of new investment. We shall not do this in great detail, since we paid a good deal of attention to this matter in another League of Nations investigation. ${ }^{4}$ Hence we only summarize the results obtained there, adding a few remarks where it seems useful.

New investment may be split up into new investment in durable goods and new investment in non-durable goods (stocks of raw materials, semi-manufactures and products: working capital).

Investment in durable goods is - in the short run - primarily determined by the margin between anticipated profit and the interest rate. Since profit rates (measured as a percentage of capital invested) show much wider fluctuations than interest rates, the latter have a less pronounced influence than the former. Profit anticipations seem to a great extent to be determined by real profits made some time before; in addition, incidental factors such as new inventions or the opening of new markets will have an influence, but it is difficult to detect this influence by means of statistical investigations, and it is at any rate remarkable how

4. J. Tinbergen, A Method and its Application to Investment Activity (Statistical Testing of Business Cycle Theories, I), League of Nations, Geneva, 1939. 
close a correlation exists between investment activity, on the one hand, and a combination of factors among which profits half a year or a year before stand out, on the other hand. ${ }^{5}$ Presumably, the influence of inventions and new markets are partly long-run influences, explaining why there are certain epochs of high and others of low investment activity, and manifesting themselves in the trend of investment; partly so-called incidental or irregular influences, showing themselves in the "residuals."

For some particular types of investment, other determinants were found to exist; those mentioned by the acceleration principle, for example, in the case of investment in rolling railway stock. It is remarkable, however, that only very faint traces of the action of this principle could be found in general investment activity. ${ }^{6}$

Investment in non-durable goods presents a particularly difficult question: it is difficult to disentangle and to summarize by a general formula the numerous factors influencing speculation in raw materials. Here our knowledge is very restricted. As to stocks of finished products, the chief impression is that there the acceleration principle works very clearly. ${ }^{7}$ There is a pronounced tendency for these stocks to move parallel - with some lag - to general activity; this implies that the increase or decrease in stocks i.e. net investment - moves parallel to the rate of increase or decrease of general activity. Possibly, also, the rate of interest exerts an influence, but this has not yet been very clearly established by statistical tests. ${ }^{8}$ It is worth noting that on this point the theorists themselves mentioning this influence are not always clear in their formulations: is it total stocks or is it investment in stocks - hence the rate of increase - that is supposed to be governed by the rate of interest?

16. Reinvestments in durable goods are, first of all, subject to the so-called echo-principle, stating that high reinvestment activity is to be expected one lifetime period after a top of high new investment in durable goods. If the average lifetime of a

5. Cf. particularly graphs III 2 (p. 56), III 3 (p. 57), III 4 (p. 58), III 5 (p. 59), III 9 (p. 81), III 10 (p. 82) and III 11 (p. 83) of the last-mentioned investigation.

6. Cf. Section 10 and Chapters IV and V.

7. Cf. J. Tinbergen, Business Cycles in the United States 1919-1932, section (2-6), p. 49. dubious.

8. The influence found in the cited investigation is rather weak and hence 
ship is taken as seventeen years, then seventeen years after a shipbuilding boom an "echo" of this boom will be found in replacement. The working of this echo is soon dissipated, since there is a considerable spread in lifetime among individual capital goods as well as among various categories. It has even often been doubted whether there is any evidence at all of its working; I think that such evidence has been presented in the case of shipbuilding ${ }^{9}$ and of automobile production. ${ }^{1}$

There are, however, important further determinants to reinvestment activity. Outstanding seems to be the influence of the general business situation: there is a clear tendency to restrict reinvestment in depression periods and to accelerate it in booms. This is clearly shown by the just cited investigations.

As to the long-run determinants, these are largely the same as those for depreciation allowances, since in the long run these two variables will tend to be equal. Hence we may refer to section 12.

17. Finally we have to consider the determinants of cash holdings ${ }^{2} M_{t+1}$. It is not necessary to indicate those of ${ }^{2} M_{t}$, since initial cash holdings have to be considered as given for each unitperiod; they are the result of past actions. The desired cash holdings ${ }^{2} M_{t+1}$ are, generally speaking, the result of weighing off against each other the advantages of a greater cash and the disadvantages of paying more interest if more credits are to be held. Before going into the motives for holding cash we may discuss some implications of this quite general statement. Indicating by $M$ the desired cash, by $Y^{I}$ the interest payments, and by $\Omega\left(M, Y^{I}\right)$ the utility function to some individual, this individual will try to maximize $\Omega$. Changes in $M$ and $Y^{I}$ are, however, not independent. Interest charges are the total of all interest due on the various credits outstanding; a credit ${ }_{T} K_{t}^{o}$ outstanding at the beginning of period $t$, and originating from the period $T$ bears a charge of ${ }_{T} K_{t}^{o} m_{T}$, where $m_{T}$ is the interest rate that existed at the period $T$. Total interest charges are, therefore, equal to

$$
Y^{I}=\Sigma T_{T} K_{t}^{o} m_{T} \text {. }
$$

9. Cf. J. Meuldijk, Der englische Schiffbau während der Periode 18701912 und das Problem des Ersatzbaues, Weltwirtschaftliches Archiv 52 (1940), p. 524; J. Einarsen, Reinvestment Cycles, Oslo, 1938.

1. The Dynamics of Automobile Demand, edited by the General Motors Corporation, New York, 1939; P. de Wolff, De vraag naar personenauto's in de Vereenigde Staten, De Nederlandsche Conjunctuur, November 1936, p. 18. 
An extension of cash holdings $M$ at the period $t$ can be obtained by an equal extension of credits ${ }_{t} K_{t}^{o}$, which bear an interest charge of $m_{t}$, interest rate at period $t$. The maximum value for $\Omega$ is obtained for such a value of $M$ that

$$
\frac{d \Omega}{d M}=\frac{\partial \Omega}{M}+\frac{\partial \Omega}{\partial_{t} K_{t}^{o}}=\frac{\partial \Omega}{\partial M}+\frac{\partial \Omega}{\partial Y^{I}} m_{t}=0 .
$$

This equation expresses in the well-known way that the increase in utility caused by the increase in $M$ just outweighs the decrease as a consequence of the increased interest charges. It may be solved - in principle, at least - for $M$ and then yields a relation

$$
M=F\left(m_{t} \ldots\right)
$$

between $M$ and $m_{t}$, which in a sense is Keynes' liquidity preference function (but then related to total cash holdings, not to "inactive balances" only). ${ }^{2}$

One point we want to emphasize is that this function $F$ depends not only on the rate of interest $m_{t}$ during the period under consideration, but also on a number of earlier interest rates, determining the interest charges on older credits. Another point is that it is not always possible to adapt $M$ to one's desires simply by changes in credits outstanding at the rate of $m_{t}$. From the moment where all recent credits outstanding are redeemed and a further desire for a diminishing of cash holdings would exist, the individual under discussion has to redeem "older" credits if possible - and this means that another, viz. an "older" interest rate $m_{T}$ comes into play. This implies that $M_{t+1}$ cannot, under all circumstances, be considered as an invariant function of $m_{t}$ alone; which seems to be a clear departure from the Keynesian doctrine. One of two alternatives comes instead: either older $m_{T}$ 's come into the liquidity preference function $(17,3)$, or if no opportunities for further redemptions exist - they may be forbidden by the older contracts - a value of $M$ deviating from that in $(17,3)$ will be chosen by the individual.

The further determinants appearing in $(17,3)$ will be those so well described by Keynes; they are the incorporations of the transactions, precautionary and speculative motives and the desire for investment finance. The transactions motive, for example, leads to total transactions as a determinant; further,

2. Cf. G. Haberler, Prosperity and Depression, 3d edition, Geneva, 1941, p. 210. 
such factors as the rate of increase of the price level of both goods and securities may come in, or the fear for illiquidity as a consequence of a crisis. This latter factor will be of particular importance shortly after a crisis.

18. A few words may be said about the length of the elementary period. As a minimum this period should be equal to the period for which the rate of interest in consideration is fixed; for most rates this will be one day. It does not seem necessary that during this period plans are not changed, as Ohlin claims. ${ }^{3}$ The process of the formation of the interest rate is a process of trial and error, as we have seen, if we use a semi-static analysis (cf. section 10 above) and during this process plans may be changed.

Taking a day for the elementary period means making a very detailed analysis. For most practical investigations it will be convenient - and, in our opinion, quite acceptable - to take longer periods of reference, such as months, years, or even decades; this last period, if one is interested in long-term movements of interest rates. There is another reason why taking such longer periods may be useful. As Lerner ${ }^{4}$ rightly observes, a certain minimum length is required in order to permit all subjects involved to adapt their holdings of credits and cash to the interest rate; if we want to assume - for reasons of simplification - that such an adaptation takes place, we are obliged to take such a longer period. Or, to put it the other way round: if we take a very short period of reference, such as a day, we must, in accordance with what was said in section 17, admit that in the liquidity preference function other, "older" interest rates play an important rôle and that the Keynesian approximation with only the present rate is inadequate.

It is perhaps superfluous, but at any rate useful, expressly to state that the period of reference now discussed is not necessarily the same as one of the lags discussed in sections 9 and 11 ; in particular, Lutz ${ }^{5}$ has made a number of interesting points on the implications of this fact.

Neither is the elementary period the same as the period over which the financial plans are made, referred to above. For the

3. B. Ohlin, Some notes on the Stockholm Theory of Savings and Investment, Economic Journal XLVII (1937), p. 61.

4. A. P. Lerner, Alternative Formulations of the Theory of Interest, Economic Journal XLVIII (1938), p. 211.

5. F. A. Lutz, The Outcome of the Saving-Investment Discussion, this JoURNAL, LII (1938), p. 588. 
flotation of a bond issue, for example, a plan will be made referring to some decades, dependent, perhaps, on the lifetime of some capital goods involved or on the presumable period of peace in which a war loan is redeemable. Particularly for the bond market it is clear that if we take a very short elementary period - to be justified by the fact that a quotation of bonds is made up every day the chance is very great that not all holders of these securities will, in each elementary period, adapt their holdings to the state of the market.

If we take longer periods of reference we do get, of course, a more approximative result. It is equivalent to neglecting a number of links in the process of adaptation; it implies a type of analysis nearer to static theory (cf. section 10). For some purposes, particularly for the explanation of the long-run trend of interest rates, it will be very useful, however. Taking a long period of reference has one very important consequence: the influence of the flow items in our market equation $(5,6 ; 6,6 ; 7,3$ or 8,1$)$ becomes more and more preponderant as compared with that of the stock items, and hence the influence of the liquidity preference schedule diminishes in favor of that of savings and investment determinants.

19. Before discussing (in Part II, below) some applications of our market formula, let us consider for a moment the controversial formulations by Keynes and what he calls classical authors. The essence of the Keynesian treatment of the problem of determining the rate of interest may thus be summarized:

(a) The rate of interest cannot be determined by an equation: savings = investment, where savings represents the supply of, and investment represents the demand for investible funds; the impossibility of doing so is a consequence of the fact that the adaptation of savings to investment is obtained by income changes rather than changes in interest rates. In mathematical language, not the rate of interest $m$, but (national) income $Y$ is the independent variable in the equation savings = investment.

(b) Hence, the determinants of savings and investment do not influence $m$, since for any value of $m$ there is equality of savings and investment.

(c) The rate of interest, on the other hand, is determined by the liquidity preference function, connecting the quantity of money with $m$.

(d) This implies that the rate of interest must be understood 
by a stock analysis, viz. an analysis of the stock of money present at a given moment, rather than by an analysis of the flows of savings and investment per unit period.

There is some advantage in commenting on these statements with the help of a concrete case, and we choose our simplest model A (equation 5,6) as such a case. The first point to be emphasized is that Keynes" "Savings" are not ours; indicating his by $S_{t}^{K}$, we have:

$$
S_{t}^{K}=\mathrm{S}_{t}+{ }^{1} H_{t}
$$

where ${ }^{1} H_{t}$ represents total hoarding (intentional ${ }^{1} H_{t}{ }^{\prime}$ and unintentional $\left.{ }^{1} H_{t}^{\prime \prime}\right)$ by families:

$$
{ }^{1} H_{t}={ }^{1} M_{t+1}-{ }^{1} M_{t}={ }^{1} H_{t}{ }^{1}+{ }^{1} H_{t}{ }^{\prime}
$$

The second point is, that the equations: "demand for investible funds equals supply of such funds" and "Keynesian savings equal investment" are not identical; the first one runs, in our symbols:

whereas the second is:

$$
S_{t}+M_{t}^{N}+{ }^{2} M_{t}=I_{t}+{ }^{2} M_{t+1}
$$

$$
S_{t}^{K}=S_{t}+{ }^{1} H_{t}=I_{t}
$$

Nor is there a contradiction between these two equaiions: Deducting $(19,4)$ from $(19,3)$ we obtain:

$$
M_{t}^{N}+{ }^{2} M_{t}=H_{t}+{ }^{2} M_{t-1}
$$

which may be written in either of two forms:

$$
\begin{array}{ll}
M_{t}^{N}+{ }^{2} M_{t}+{ }^{1} M_{t}={ }^{2} M_{t+}+{ }^{1} M_{t+1} & \text { ("stock analysis") } \\
M_{t}^{N}={ }^{1} H_{t}+{ }^{2} M_{t+1}-{ }^{2} M_{t} & \text { ("flow analysis") }
\end{array}
$$

Of these two equations, the first expresses that the amount of money made avajlable by the banks (money already present at beginning of period: ${ }^{1} M_{t}+{ }^{2} M_{t}$, plus new creation of money $M_{t}^{N}$ during period) equals the demand for money ${ }^{1} M_{t+1}+{ }^{2} M_{t+1}$ at the end of the period, determined by the liquidity preference functions of families and firms. The second expresses that the newly created money equals the net flow of hoarding by families and business firms. As indicated in brackets, the first equation takes the form of a stock analysis, the second of a (net) flow analysis. As Ohlin has rightly pointed out, ${ }^{6}$ these two ways of representing the situation (he calls them "gross" and "net" formulation) are equivalent. In fact, their relation is the same as between a function and its differential coefficient (more exactly: its first dif-

6. B. Ohlin, loc. cit., in particular pages 224 and 225 . 
ference) or between the integral (more exactly: the cumulation) of a function and that function.

Nevertheless, the whole controversy between stock and flow analysis is not solved with this statement. There are two further questions involved. The first is that, dependent on the determinants (or, if one likes, the independent variables) behind these entities, one of the two formulations may be a better instrument of analysis than the other. If it were true that the total stock of money present at any moment is adapted immediately to the then prevailing rate of interest and ${ }^{2} M_{t+1}+{ }^{1} M_{t+1}$, were an invariant function of that rate, the stock analysis would be a better instrument. For if the stock ${ }^{2} M_{t+1}$, for example, is a function of $m_{t}$ only, then the flow ${ }^{2} M_{t+1}-{ }^{2} M_{t}$ is a function of the two interest rates $m_{t}$ and $m_{t-1}$, and hence a more complicated expression. But if only the flow of new money is dependent on that rate, whereas the older "parts" of the stock are dependent on "older" rates, the flow analysis is the more appropriate instrument.

For now the stock would be a more - and even a far more complicated expression in terms of the interest rate: it would, in principle, depend on all previous interest rates. Thus there remains the question to be answered, which of the two - or even more, namely, "mixed" - alternatives is closest to reality. Lerner rightly argues that the flow analysis in its simplest form cannot be right: a certain interest rate cannot induce people continuously to hoard a certain amount of money per time unit. On the other hand, our analysis in section 17 seems to prove that the pure stock analysis - at least, if applied to very short periods - is not correct either. It is only so if we do not consider too short periods; it is an approximation.

This brings us into the second question. It is useful to make a distinction between two sorts of flow analysis, net flow and gross flow analysis. The difference can best be clarified by reminding the reader of our concepts (cf. section 2) $K_{t}^{n}$ and $K_{t}^{N}$, where $K_{t}^{n}$ was the total amount of new credits accorded during time period $t$ and $K_{t}^{N}$ was the net increase in credits outstanding; we call $K_{t}^{n}$ the gross flow and $K_{t}^{N}$ the net flow of new credits. (Of course, similar distinctions may be made for cash holdings). The connection between $K_{t}^{n}$ and $K_{t}^{N}$ is given by equation $(2,4)$ : $K_{t}^{N}=K_{t}^{n}-K_{t}^{E}$, where $K_{t}^{E}$ represents credits expired. The difference in behavior between $K_{t}^{N}$ and $K_{t}^{n}$ is best illustrated by the 
consideration of two special cases. First, assume that all credit contracts are accorded for one elementary time period only. That implies that credits outstanding at the end of period 1 equal credits accorded during that period:

$$
K_{2}^{o}=K_{1}^{n}
$$

and credits expiring during period 1 equal credits outstanding the beginning of period 1 :

$$
K_{1}^{E}=K_{1}^{o}
$$

Equation $(19,8)$ expresses that now stock=gross flow; for the net flow, however, we still have that it equals the rate of increase in stock.

Secondly, assume that all credits are accorded for two elementary time periods. This means that, instead of $(19,9)$, we now get:

$$
K_{1}^{E}+K_{2}^{E}=K_{1}^{o}
$$

telling that credits outstanding at the beginning of period 1 will now be expiring during the next two periods. Now since

$$
K_{3}^{o}=K_{1}^{o}+K_{i}^{N}+K_{2}^{N}=K_{1}^{o}+\left(K_{1}^{n}-K_{1}^{E}\right)+\left(K_{2}^{n}-K_{2}^{E}\right)
$$

it follows that:

$$
K_{3}^{o}=K_{1}^{n}+K_{2}^{n}
$$

or: the stock equals the gross flow taken over two consecutive periods. Still the net flow, if taken over these two periods, equals the rate of incre:tse in the stock. The stock therefore equals the cumulation of the gross flow over a finite time interval, and the cumulation of the net flow over an infinite time interval. The relations get more complicated if the contracts are of unequal length, and we cannot go into this here. But it will be clear that there is conceivable a third type of theory, namely, one where the simplest description of reality is obtained by expressing the gross flow by some function of the independent variables. From the preceding sections it follows that we consider this the best solution of the stock-andflow antithesis.

To state clearly what determinants will appear in the system of equations, we rewrite the two equations, in both the "classical" and the Keynesian form, using function symbols where that seems appropriate. 
"Classical":

$$
\begin{gathered}
S_{t}\left(Y_{t}, Y_{t-1}, m_{t}\right)+M_{t}^{N}\left(m_{t}\right)+{ }^{2} M_{t}=I_{t}\left(Y_{t-1}, m_{t}\right)+{ }^{2} M_{t+1}\left(Y_{t}, m_{t}\right) \\
Y_{t}=C_{t}\left(Y_{t}, Y_{t-1}\right)+I_{t}\left(Y_{t-1}, m_{t}\right)
\end{gathered}
$$

Keynesian:

$$
\begin{gathered}
M_{t}^{N}\left(m_{t}\right)+{ }^{2} M_{t}+{ }^{1} M_{t}={ }^{2} M_{t+1}\left(Y_{t}, m_{t}\right)+{ }^{1} M_{t+1}\left(Y_{t}, m_{t}\right) \\
Y_{t}=C_{t}\left(Y_{t}, Y_{t-1}\right)+I_{t}\left(Y_{t-1}, m_{t}\right) .
\end{gathered}
$$

In addition, the identity connecting $C, S$ and ${ }^{1} M$ (our equation (4.1) ) may be repeated:

$$
Y_{t}=C_{t}+S_{t}+{ }^{1} M_{t+1}-{ }^{1} M_{t} .
$$

This, however, is indeed an identity, meaning that it must be true, for any value of $Y_{t}$ and $m_{t}$, whereas the above equations are conditions to be fulfilled by $Y_{t}$ and $m_{l}$.

Generally speaking, the pair of equations (C 1) and (C 2), or the equivalent pair (K 1) and (K 2), determines simultaneously the variables $Y_{t}$ and $m_{t}$. The determinants occurring in these equations are those of $S, I,{ }^{2} M_{t+1}, C$, or, since there is a definitional connection (4.1) between $S, C$ and ${ }^{1} M$, the determinants of $S, I,{ }^{2} M_{t+1}$ and ${ }^{1} M_{t+1}$. The latter two taken together forming the liquidity preference (of firms and families, respectively) it may be concluded that, generally speaking, the determinants of (active) savings, investments and liquidity preference together determine $Y_{t}$ as well as $m_{t}$. Only in the special case, where, in equation (19.6), ${ }^{2} M_{t+1}$ as well as ${ }^{1} M_{t+1}$ would only depend on $m_{t}$ and not on $Y_{b}$, Keynes' thesis that $m_{t}$ is determined by liquidity preference only, would hold. Since $Y_{t}$ generally will influence ${ }^{1} M_{t+1}$ and ${ }^{2} M_{t+1}$ through the transactions motive, this special case does not seem to be of great significance.

On the other hand it does not seem probable that in $S_{t}$ or $I_{t}$ the variable $m_{t}$ does not occur; it is probable that, at least in $I_{t}, m_{t}$ appears as an independent variable; $Y_{t}$ is not, if this is so, the only independent variable determining the amounts $S_{t}$ or even $S_{t}^{K}$.

Here we are led to exactly the same conclusion as Hicks ${ }^{7}$ and Pallander $^{8}$ - that Keynes' theory is only a special case of a more p. 147.

7. J. R. Hicks, Mr. Keynes and the Classics, Econometrica V (1937),

8. T. Pallander, Keynes' allmänna teori och dess tillämpning inom ränte-, multiplikator- och pristeorien, Ekon. Tidskrift XLIV (1942), p. 233. 
general one. This seems to have been overlooked by Lerner ${ }^{9}$ and perhaps also by Haberler, when these authors try to show that there is, in the end, no difference of opinion about facts, only about definitions, between Keynes and the "classics."

\section{II}

20. So far we have treated the credit market as a single market. It is, however, composed of various compartments, more or less isolated, with different prices. The method of dealing with this phenomenon of partial markets within the framework of the foregoing analysis may be illustrated by considering in more detail the roughest distinction between various types of credits we are accustomed to work with, namely, that between "long" and "short" credits, to be indicated by left-hand bottom indices $L$ and $S$. To fix the ideas, the border line between long and short credits may be taken at one year. There are two representative interest rates ${ }_{L} m$ and ${ }_{S} m$; say the yield on bonds and the private discount rate. Each item in the market equation has now to be split up into an item for long and one for short credits; the demand item ${ }_{N} I$, e.g. into ${ }_{L N} I$ and ${ }_{S N} I$, where ${ }_{L N} I$ may be the demand for bond (and stock) capital to finance new investments and ${ }_{S N} I$ the demand for bank credit for the same purpose ("anticipation credits"). Both will depend on the determinants relevant to new investments and, in addition, on both interest rates. In particular, it will be the relation of these two rates and the expected future long-term rate and its movements that will influence the method of financing the investments. Attempts to proceed to econometric analysis in this way have been made in my abovequoted investigation on the business cycles in the United States 1919-1932, to be discussed further in section 26.

Applying the same idea in the other items of the market equation, we get two equations, expressing the equality of demand and supply respectively for short and for long credits:

$$
\begin{aligned}
& { }_{S}^{D} K^{n}={ }_{S}^{S} K^{n} \\
& { }_{L}^{D} K^{n}={ }_{L}^{S} K^{n} .
\end{aligned}
$$

9. Loc. cit. Unfortunately Lerner's interesting paper is somewhat obscured by two circumstances. First, he is not clear about what definition for savings he assumes, and secondly, he uses the symbol $Y$ alternatively for income and for "ordinate" generally; thus he also uses $Y$ in one or two graphs to mean the interest rate, which, in view of the subject under discussion, is somewhat unfortunate. 
In order to exemplify the results that may be obtained by our instrument of analysis, let us go into somewhat greater detail.

As our special purpose for the following few sections we take the explanation of the cyclical behavior of the two interest rates. Hence we shall neglect all determinants that are only of importance for the explanation of trend movements or of very short fluctuations: only determinants showing an important and systematic cyclic component will be considered. The cyclical movement of the non-credit markets will be considered as given and will be assumed to be represented by the fluctuations in the general profit rate $z$, since most of the other economic variables show a cyclical pattern parallel to that of $z$.

Demand for short credits will chiefly be for new investment purposes, for speculation and for increasing liquidity; new investment only as far as it takes the form of investment in commodity stocks or as the credit takes the form of an anticipation credit. The supply of short credits originates from the banks. Demand for long credits will be for investment in durable goods: capital issues by public authorities, public utilities and mortgages for building or for some types of consumption credit (public authorities and the general public for as far as this demand materializes by the selling of "old securities"). The supply of long credits originates from the savings of family households and from the investment of part of the banks' resources. The concrete shape of the relation between each of these items and the two interest rates and the other determinants will depend on (i) the planning period or "horizon" of the subjects involved; (ii) the time shape of the need for or the availability of credit within that time period, determining, for example, the degree of idleness of long credits and (iii) the technical opportunities of demanding or supplying (the question whether one is or is not permitted to enter a certain market) and, closely related, the possibilities of substitution.

If, in particular, some type of investment promises a profit rate of $z$, whereas the interest rate to be paid is $m$, demand will depend on $z-m$; if, in addition, there is a possibility of lending in another market compartment at a rate $m^{\prime}$, it will also depend on $m^{\prime}-m$.

For part of the demand for short credits, namely, commercial and speculative credits, no substitution possibilities exist; they will depend on the difference between the general profit rate $z$ 
and ${ }_{s} m$ only. For advances, the substitution by a long credit exists, and hence they will, in addition, depend on ${ }_{L} m-{ }_{S} m$. We are led to a somewhat more exact theory by the following considerations. The choice may be said to be between:

(a) to continue a short credit for a period $\theta$ and then to take a long credit;

(b) to start the long credit immediately.

The first possibility implies the payment of a rate of ${ }_{s} m$ over a period $\theta$, instead of ${ }_{L} m$, and a payment of another long-term interest rate than the one now prevailing, namely, the rate expected to exist after a lapse $\theta$. If the investor bases his expectation on an extrapolation of the present movement of ${ }_{L} m$, the expected rate will be ${ }_{L} m+\theta_{L} \dot{m}$. Thus interest payments over a horizon $T$ will be, in case $(a) \theta_{S} m+(T-\theta)\left({ }_{L} m+\theta_{L} \dot{m}\right)$ and in case (b) $T_{L} m$. The choice will depend on the difference: $\theta\left({ }_{S} m-{ }_{L} m+(T-\theta)_{L} \dot{m}\right)$. From this somewhat closer examination we learn that, apart from the difference ${ }_{s} m-{ }_{L} m$ already mentioned, the choice will depend on ${ }_{L} \dot{m}$, if the expectations are based on extrapolation of the present movement. If the expression $\theta\left({ }_{S} m-{ }_{L} m+(T-\theta)_{L} \dot{m}\right)$ increases there will be a stronger demand for long credits; if it decreases, the demand for short credits will be stronger. In view of the foregoing considerations, demand for short credits may be assumed to be given by the equation

$$
{ }_{S}^{D} K^{n}=a_{1}\left(z-{ }_{S} m\right)-a_{2}\left({ }_{S} m-{ }_{L} m\right)-a_{3 L} \cdot \dot{m}
$$

The supply of short credits originates, as we stated already, from the banks. Disregarding incidental factors such as fluctuations in gold stock, it will primarily depend on the short interest rate itself, which determines the degree of profitableness of creating credit. These credits may, however, partly be used for buying bonds; this again depends on the market situation and prospects. A short credit, say, for a time period $\theta$, will yield the bank interest receipts proportional to $s m \theta$, whereas an investment in bonds yields (i) interest receipts proportional to ${ }_{L} m \theta$ and (ii) a price gain or loss proportional to $p$, the difference between the expected price of the bonds at time $t+\theta$ and the price at time $t$. Assuming again that the expected price movement is based on extrapolation of the existing movements, it may be deduced from ${ }_{L} m$ and ${ }_{L} \dot{m}$ in the following way. Let the initial bond price be 1 , then the price 
at time $t+\theta$ will be

the price gain will be

$$
\frac{{ }_{L} m}{{ }_{L} m+{ }_{L} \dot{m} \theta}
$$

$$
\frac{{ }_{L} m}{{ }_{L} m+{ }_{L} \dot{m} \theta}-1=-\frac{{ }_{L} \dot{m} \theta}{{ }_{L} m}
$$

approximately. Together with interest receipts this shows a difference with interest receipts in the short credit case of

$$
\left({ }_{S} m-{ }_{L} m+\frac{{ }_{L} \dot{m}}{{ }_{L} m}\right) \theta
$$

Again the supply of short credits will therefore be the greater, the higher this difference is. Taking account of this substitution effect as well as with the absolute profits to be obtained by credit creation, the supply of short credits will be, in the simplest case:

$$
{ }_{S}^{S} K^{n}=\beta_{1 S} m+\beta_{2}\left({ }_{S} m-{ }_{L} m\right)+\beta_{3 L} \dot{m} .
$$

The demand for long credits will chiefly be governed by the difference between profit expectations, which we assume to be dependent on the actual profit rate $z$, and the long-term interest rate ${ }_{L} m$. For another part, e.g. as far as it is demanded by public authorities for covering deficits and for consumption purposes, it will depend on national income and even in a negative way; but since the fluctuations in national income are closely correlated with those in $z$, this only means adding a term of a type already introduced. It may be, however, that this part of demand is not so much influenced by the interest rate itself, and hence the term with ${ }_{L} m$ need not have numerically the same coefficient as the one with $z$. In addition, also here, a substitution effect - the complement to the effect discussed for the demand for short credits - is to be expected. It will be based on the same variables as the latter, but will show the opposite sign. Hence the demand for long credits will be of the following shape:

$$
{ }_{L}^{D} K^{n}=\gamma_{1} z+\gamma_{2}\left(s m-{ }_{L} m\right)+\gamma_{3 L} \dot{m}-\gamma_{4 L} m .
$$

Finally, the supply of long credits originates from two sources, private and banking investments. Private investments may be out of current savings, which largely depend on national income and hence approximately on $z$, and out of accumulated wealth from older savings, held in money form. The latter may be assumed 
to depend on $\int_{0}^{t} z d t$, the accumulated value of previous profit rates - because of the close correlation between profit rates and national income. They may depend also on the long-term rate of interest, but do not seem to do so in a very marked way. Investment by banks will be much more influenced both by that rate of interest and by the substitution motive, which again is the counterpart of the substitution effect in the supply of short credits. In addition it depends on liquidity considerations which will, however, largely be determined by the general business situation, i.e. by $z$. Hence we may put:

$$
{ }_{L}^{S} K^{n}=\delta_{1} z-\delta_{2}\left({ }_{S} m-{ }_{L} m\right)-\delta_{3 L} \dot{m}+\delta_{4 L} m+\delta_{5} \int_{0}^{t} z d t .
$$

One interesting implication of the above analysis may be emphasized beforehand - the rôle attributed to savings. If it is true that family savings are chiefly led to the long-term credit market, two conclusions may be drawn: (i) they will not influence in a direct way the short interest rate, and (ii) even their influence on the long-term interest rate will be very smooth, because this latter is chiefly governed by the accumulated fund of anterior and present savings: a considerable change in annual savings only means a slight change in this fund. Abundance of savings will not therefore result in a sudden change in interest rates; shortage will only do so if the banking system is operating exactly at the limit of its reserves and cannot even supply the smallest extra amount of complementary means of payment. These conclusions seem rather interesting. The specifications discussed in this section transform the equations $(20,1)$ and $(20,2)$ into:

$$
\begin{gathered}
a_{1}\left(z-{ }_{S} m\right)-a_{2}\left({ }_{S} m-{ }_{L} m\right)-a_{3 L} \dot{m}=\beta_{1 S} m+\beta_{2}\left({ }_{S} m-{ }_{L} m\right)+\beta_{3 L} \\
\gamma_{1} z+\gamma_{2}\left({ }_{S} m-{ }_{L} m\right)+\gamma_{3 L} \dot{m}-\gamma_{4 L} m=\delta_{1} z-\delta_{2}\left({ }_{S} m-{ }_{L} m\right)- \\
\quad-\delta_{3 L} \dot{m}+\delta_{4} m+\delta_{5} \int_{0}^{t} z d t
\end{gathered}
$$

21. Let us investigate somewhat further the consequences of these equations, in order to find out whether they explain some of the most characteristic features in the cyclical behavior of interest rates. The equations are rather complicated: they are simultaneous equations; for ${ }_{L} m$ even differential equations, with a righthand member. In order to clarify the connections involved, we 
may start with a very special case and gradually proceed to more complicated cases. Since statistical tests, to be discussed later (section 26), have suggested that the influence of the terms with $L^{i n}$ is weak, we start by omitting them. Further, we assume for a while that the other substitution terms (those with ${ }_{S} m-{ }_{L} m$ ) also vanish. This means considering the two markets as separate markets. The equations now become:

$$
\begin{gathered}
\left(a_{1}+\beta_{1}\right)_{S} m=a_{1} z . \\
\left(\gamma_{4}+\delta_{4}\right)_{L} m=\left(\gamma_{1}-\delta_{1}\right) z-\delta_{5} \int_{0}^{t} z d t .
\end{gathered}
$$

Two cases may be distinguished: (i) $\delta_{5}=0$ and (ii) $\delta_{5}>0$. In the former case, the two interest rates move parallel with each other and with $z$ if $\gamma_{1}>\delta_{1}$. Their amplitudes are proportional to $\frac{a_{1}}{a_{1}+\beta_{1}}$ and $\frac{\gamma_{1}-\delta_{1}}{\gamma_{4}+\delta_{4}}$, respectively. Since the numerator of the second fraction is a difference, there is a good chance that the second fraction is smaller than the first and hence that ${ }_{L} m$ shows less pronounced fluctuations than $s_{s} m$. In non-mathematical terms, the explanation would be that, during the business cycle, both the demand and the supply schedules for long credits shift - in the same direction - whereas for short credits only the demand schedule shifts (the structure of the banks, determining the supply schedule, being constant) and hence the short-term rate shows larger fluctuations than the long-term rate. If, however, $\delta_{1}>\gamma_{1}$, the fluctuations of the two rates would be opposite to each other, which does not fit the facts. Assuming (ii) that $\delta_{5}>0$ would mean the introduction, in the movements of ${ }_{L} m$, of a component leading the general cycle by one-quarter of a period, and would therefore mean that $m$ would show a more or less pronounced lead to that cycle, which does not fit the facts either.

Now let us no longer assume that the two markets are isolated, and study the consequences of the introduction of the substitution terms with ${ }_{S} m-{ }_{L} m$. We now get:

$$
\begin{gathered}
\left(a_{1}+a_{2}+\beta_{1}+\beta_{2}\right)_{S} m-\left(a_{2}+\beta_{2}\right)_{L} m=a_{1} z . \\
\left(\gamma_{2}+\delta_{2}\right)_{S} m-\left(\gamma_{2}+\gamma_{4}+\delta_{2}+\delta_{4}\right)_{L} m=\left(-\gamma_{1}+\delta_{1}\right) z+\delta_{5} \int^{t} z d t
\end{gathered}
$$


These equations may be written in the simpler form:

$$
\begin{gathered}
{ } m-\theta_{1 L} m=\theta_{2} z \\
\theta_{3 S} m-{ }_{L} m=\delta_{1}{ }^{\prime} z-\delta_{5}{ }^{\prime} \int_{0}^{t} z d i
\end{gathered}
$$

where all $\theta$ 's are $<1$, since $\theta_{1}=\frac{a_{2}+\beta_{2}}{a_{1}+a_{2}+\beta_{1}+\beta_{2}}$

$$
\begin{aligned}
& \theta_{2}=\frac{a_{1}}{a_{1}+a_{2}+\beta_{1}+\beta_{2}} \\
& \theta_{3}=\frac{\gamma_{2}+\delta_{2}}{\gamma_{2}+\gamma_{4}+\delta_{2}+\delta_{4}}
\end{aligned}
$$

Moreover, $\delta_{1}{ }^{\prime}=\frac{\delta_{1}-\gamma_{1}}{\gamma_{2}+\gamma_{4}+\delta_{2}+\delta_{4}}$ and $\delta_{5}{ }^{\prime}=\frac{\delta_{5}}{\gamma_{2}+\gamma_{4}+\delta_{2}+\delta_{4}}$

Assuming again, for a moment, (i) $\delta_{5}{ }^{\prime}$ to be zero, the solution of the equations $(21,5)$ and $(21,6)$ may be written in the form:

$$
\begin{aligned}
& { }_{s} m\left(1-\theta_{1} \theta_{3}\right)=\left(\theta_{2}-\theta_{1} \delta_{1}{ }^{\prime}\right) z \\
& { }_{L} m\left(1-\theta_{1} \theta_{3}\right)=\left(\theta_{3} \theta_{2}-\delta_{1}{ }^{\prime}\right) z .
\end{aligned}
$$

If now $\delta_{1}{ }^{\prime}<\theta_{3} \theta_{2}$, we have: $\theta_{3} \theta_{2}<\theta_{2}$ and $\delta_{1}{ }^{\prime}>\theta_{1} \delta_{1}{ }^{\prime}$ from which it follows that $\theta_{3} \theta_{2}-\delta_{1}{ }^{\prime}<\theta_{2}-\theta_{1} \delta_{1}{ }^{\prime}$, or that the amplitude of ${ }_{L} m$ is less than that of ${ }_{S} m$, a result similar to that obtained formerly.

Assuming, then, (ii) $\delta_{5}{ }^{\prime}$ to be positive, we get an additional term in the solutions for both interest rates. It may, however, be proved that this term is relatively stronger for ${ }_{L} m$ than for ${ }_{S} m$; therefore we should still obtain a pattern not in conformity to reality ${ }_{L} m$ would lead $S_{S} m$ and both would lead the general cycle. The same may be proved for the re-introduction of the ${ }_{L} \dot{m}$-terms.

22. So far these results are none too good; some of the most characteristic features of reality, namely, that both the short and the long rate lag behind the general cycle and the long rate more than the short, have not yet been explained, even by the introduction of the dynamic terms with ${ }_{L} \dot{m}$. There is, however, another dynumic element that has to be introduced; demand for long credits, as far as it takes the form of capital issues, ordinarily lags behind its determinants, since this type of demand is often provisionally satisfied by the use of anticipation credits: industrial demand by bank credits, government demand by the floating of treasury bills. Hence the terms $\gamma_{1} z-\gamma_{4 L} m$ in equation $(20,5)$ 
may be lagged; e.g. over half a year. Taking this period as the unit of time, we write $\gamma_{1} z_{-1}-\gamma_{4 L} m_{-1}$ instead, and try to solve the equations proceeding, as before, from the simpler to some of the more complicated cases. Leaving out, to begin with, all substitution terms and the term with $\int_{0}^{t} z d t$, we have:

$$
\begin{gathered}
\left(a_{1}+\beta_{1}\right)_{S} m=a_{1} z \\
\delta_{4 L} m+\gamma_{4 L} m_{-1}=\gamma_{1} z_{-1}-\delta_{1} z .
\end{gathered}
$$

The first of these equations again tells us that $s m$ will fluctuate parallel with $z$; the second is more complicated, and we shall only solve it approximately. The left-hand member may be written as $\left(\delta_{4}+\gamma_{4}\right)_{L} m_{-\theta}$, where $\theta \sim \frac{\gamma_{4}}{\delta_{4}+\gamma_{4}} ;$ the right-hand member as $-\gamma_{1}\left(z-z_{-1}\right)+\left(\gamma_{1}-\delta_{1}\right) z$. In this latter expression, the first term represents a component showing a lag of a quarter of a cycle approximately; the second either (if $\gamma_{1}>\delta_{1}$ ) no lag or (if $\gamma_{1}<\delta_{1}$ ) one of half a cycle. The result is that ${ }_{L} m$ shows a lag behind the general cycle, which is either somewhere between $\frac{1}{4} T-\theta$ (where $T$ is the length of the cycle) and $-\theta$ (i.e. a lead of $\theta$ ) or somewhere between $\frac{1}{4} T-\theta$ and $\frac{1}{2} T-\theta$, both cases in the neighborhood of $\frac{1}{4} T-\theta$, since the coefficient $\gamma_{1}-\delta_{1}$ of the $z$ term is smaller than that of the $z-z_{-1}$ term. Thus we get a lag in, but a somewhat pronounced one.

Let us now introduce again the terms with ${ }_{S} m-{ }_{L} m$; this yields the equations:

$$
\begin{gathered}
\left(a_{1}+a_{2}+\beta_{1}+\beta_{2}\right)_{S} m-\left(a_{2}+\beta_{2}\right)_{L} m=a_{1} z \\
\left(\gamma_{2}+\delta_{2}\right)_{S} m-\left(\gamma_{2}+\delta_{2}+\delta_{4}\right)_{L} m=-\gamma_{1} z_{-1}+\delta_{1} z+\gamma_{4 L} m_{-1}
\end{gathered}
$$

As in section 21, we transform them into

$$
\begin{gathered}
{ }_{S} m-\theta_{1}{ }_{L} m=\theta_{2} z \\
\theta_{3}{ }_{S} m-{ }_{L} m=-\gamma_{1}{ }^{\prime} z_{-1}+\delta_{1}{ }^{\prime} z+\gamma_{4}{ }^{\prime}{ }_{L} m_{-1}
\end{gathered}
$$

where $\theta_{1}$ and $\theta_{2}$ have the same meaning as before, $\theta_{3}=\frac{\gamma_{2}+\delta_{2}}{\gamma_{2}+\delta_{2}+\delta_{4}}$,

$$
\gamma_{1}{ }^{\prime}=\frac{\gamma_{1}}{\gamma_{2}+\gamma_{4}+\delta_{2}} \text { and } \delta_{1}{ }^{\prime}=\frac{\delta_{1}}{\gamma_{2}+\gamma_{4}+\delta_{2}}
$$

The solution may now be approximated by the following procedure: provisionally we consider $m_{-1}$ as given, and we deduce, 
from $(22,5)$ and $(22,6)$ :

$$
\begin{gathered}
{ }_{S} m\left(1-\theta_{1} \theta_{3}\right)=\left(\theta_{2}-\theta_{1} \delta_{1}{ }^{\prime}\right) z+\theta_{1}\left(\gamma_{1}{ }^{\prime} z_{-1}-\gamma_{4}{ }^{\prime} m_{-1}\right) \\
{ }_{L} m\left(1-\theta_{1} \theta_{3}\right)=\left(\theta_{3} \theta_{2}-\delta_{1}{ }^{\prime}\right) z+\left(\gamma_{1}{ }^{\prime} z_{-1}-\gamma_{4}{ }_{L}{ } m_{-1}\right)
\end{gathered}
$$

For $(22,8)$ we write:

$$
\begin{aligned}
& \left(1-\theta_{1} \theta_{3}+\gamma_{4}{ }^{\prime}\right)_{L} m_{-\theta}=\left(\theta_{3} \theta_{2}-\delta_{1}{ }^{\prime}+\gamma_{1}{ }^{\prime}\right) z_{-\eta} \\
& \text { where } \theta=\frac{\gamma_{4}{ }^{\prime}}{1-\theta_{1} \theta_{3}} \text { and } \eta=\frac{\gamma_{1}{ }^{\prime}}{\theta_{3} \theta_{2}-\delta_{1}{ }^{\prime}} .
\end{aligned}
$$

The exact behavior of ${ }_{L} m$ can only be determined, on the basis of this approximate solution, when the various coefficients are known numerically. What we may show is, however, that now at least the possibility exists of a result in accordance with the real facts. If $\theta_{3} \theta_{2}-\delta_{1}{ }^{\prime}+\gamma_{1}{ }^{\prime}$ is a small number, ${ }_{L} m$ will have a small amplitude, again chiefly because both the supply and the demand schedule shift upwards during the cycle. If further $\eta>\theta,{ }_{L} m$ is lagged behind $z$. The smallness of ${ }_{L} m$ 's amplitude would make it legitimate to neglect, in $(22,7)$, the term with ${ }_{L} m_{-1}$; hence $(22,7)$ would yield us the solution for $s m$.

In addition, a comparison of $(22,7)$ and $(22,8)$ shows that ${ }_{s} m$ and ${ }_{L} m$ are both composed of two $z$ terms, one without and one with a lag, of which the former is stronger for $s m$, whereas the latter is stronger for ${ }_{L} m$. This implies that both interest rates lag behind the general cycle, but ${ }_{L} m$ more than ${ }_{S} m$, in accordance with reality. ${ }^{1}$

23. We shall conclude our digest of recent literature on the formation of interest rates by a few paragraphs on the results of econometric analysis in this field obtained up to now. This short survey will be given the combined character of a review and of a program. What are the most conspicuous features of the level and the course of interest rates in the principal countries demanding explanation? They may be classified as follows:

1. For an interesting analysis of this relation of J. R. Hicks, Mr. Hawtrey on Bank Rate and the Long-Term Rate of Interest, The Manchester School of Economic and Social Studies X (1939), p. 27. P. Lorenz (Eine Differentialgleichung der Wirtschaftsforschung und ihr Integral, Blätter für Versicherungsmathematik und verwandte Gebiete, Beilage zur Zeitschrift für die gesammte Vers.-Wissenschaft, Bd. zg. Heft 3, p. 212) has gone one step further and also proposed a "law" governing the process of mutual adaptation of the two rates, without, however, giving a clear-cut theoretical foundation of that law. 


\section{Differences in level.}

Between countries. During the second half of the nineteenth century the levels of interest rates in the chief countries approached each other very closely; that of the United States having been considerably higher, at the middle of that century, than that of the European countries. After the first World War the rate of interest in Germany was considerably higher than elsewhere in western countries. Moreover, the rate of interest for first-rate bonds was in China very much higher than in a country like India, economically comparable to China; in India it does not surpass by very much the level in Great Britain.

Between various types of interest rates. As a rule, yield on firstrate bonds is lower than yield on stocks; there are, however, remarkable exceptions; for the United States after 1919 and Germany, 1870-1900. ${ }^{2}$ Very large differences between rates for large credits to public authorites or concerns and for small credits to the population exist, notably in the far eastern countries.

\section{Characteristics of movements.}

Trend movement. The general trend throughout the nineteenth and twentieth century is a falling one.

Long cycles. Superimposed on this trend there are long cycles which coincide, roughly speaking, with those of the general price movement.

Shorter cyclical movements show themselves especially in shortterm rates, where they are very pronounced. They lag somewhat behind the general cycle, as is expressed in the C-curve of the Harvard Barometer, and in addition they show the short "American" cycle (with a three- to four-year period) not only in the United States, but also in European countries. The long-term rate of interest practically does not show the normal cycle at all.

Influence of the World Wars. There is a pronounced rise in interest rates during and shortly after the first and no such rise during the second World War.

Seasonal and short irregular fluctuations may be left out of consideration in this essay.

24. As for the differences in level, they do not lend themselves so

2. Cf. Het verloop op langen termijn van de rentestanden, Statistische en Econometrische Onderzoekingen, ed. by Centraal Bureau v. d. Statistiek, The Hague, 1943, Nr. 2/3, p. 6. 
well to econometric analysis as the characteristics of movements. Nevertheless, more could be done than has been accomplished so far. I do not know thorough studies on the high level of interest rates in the United States at the middle of the nineteenth century; the high level in Germany after the first World War, however, has found ample observation, albeit not along typically econometric lines of approach. ${ }^{3}$ An econometric analysis of various sorts of interest rates in western and less developed countries has not been presented, as far as I am aware. Certainly it will be difficult to find adequate measures for the differences in risk premium that often will be necessary to explain the divergencies. Nevertheless, it does seem useful to embark upon a more systematic quantitative analysis of the phenomena enumerated.

25. As for the characteristics of movements, let us first consider somewhat more closely the long-term movements and apply our theoretical scheme to the explanation of these movements. This we may do by using a long period of reference; or to put it more exactly, to add up the market equation for a series of consecutive unit periods. This procedure will to some extent simplify matters. First, the "stock items" in the equation will largely cancel out against each other; taking as an example market equation $(8,1),{ }^{2} M_{t+1}$ for the first elementary period stands against $-{ }^{2} M_{t+1}$ for the second elementary period, and hence cancels out. This need not be exactly so, since in the equation for the first period ${ }^{2} M_{t+1}$ represents an expected value and in that for the second period an ex-post value. If we may assume that, over a long period, there are no systematic differences between expectations and realizations, however, we may neglect that fact. Hence, in the equation obtained by the adding up, for all elementary periods included in our long period of reference, of the market equation, we are only left with the stock quantities referring to the beginning and the end of the long period, and the equation obtained is of quite the same type as our elementary market equation. This implies, however, that the magnitude of the flow terms is now much more preponderant in comparison with that of the stock terms: the flow terms are approximately proportional to the length of the period of reference and the stock items are not.

A second consequence of the consideration of a long period

3. Cf. c.g. E. Welter, Die Ursachen des Kapitalmangels in Deutschland, Tübingen, 1931 . 
of reference is that items showing a rapid movement will lose in significance: the separate summands will, to some extent, cancel out against each other. Such may be the case, for example, with credit creation and with hoarding flows. These items will, during the course of one business cycle, alternatively show negative and positive values and their total will be rather small. The same applies to the elementary periods before and after a panic.

All this means an approach to "classical" or to static theories: the influence of the steady flows of savings, depreciation allowances, new investment, reinvestment purchases and sales of "old" securities and their determinants, becomes preponderant. But a complete approach to these theories is not possible; in pure statics, for example, cash holdings for risks do not make sense, but in reality they do, even in the long run.

An important feature of purely statical theory is that the rate of interest is only dependent on "real" or physical, not on nominal, factors. For example, a doubling of the money in circulation will, according to this type of theory, only lead to a doubling of nominal prices and money items, but not to a change in any "real" variables and hence not in the rate of interest. To put it another way, the rate of interest, being the ratio between the income of the capital owner and his capital, will not be influenced in the long run, since both his income and his capital will have doubled. It is therefore doubtful whether the long-term correlation between the price level and the interest rate can be easily understood. Macaulay ${ }^{4}$ tried to do so by the following reasoning, which he unfortunately has not translated into a close quantitative approach. Starting from the hypothesis that the relevant credit contracts are long-term contracts, and the interest charges therefore remain constant if the general price level rises, he points to the increases in profits and hence in demand for further investments that follow. Against this increased demand he sees no adequately increased supply of credits, since incomes will not have risen so much. In vicw of the great increase in profits, this is not clear; it may be true, as Macaulay contends, that salaries and incomes of bond proprictors will not have risen so much, but incomes of entrepreneurs will.

Another attempt to account for the correlation between price

4. Some Theoretical Problems Suggested by the Movements of Interest Rates, etc., New York, 1938, p. 206. 
level and interest rates, and at any rate theoretically sounder, although it may seem somewhat artificial, is the one undertaken by Irving Fisher. ${ }^{5}$ Fisher points to the influence of a persisting rate of increase in the price level on the demand for and supply of credits. Such a rate of increase means a continuous depreciation of money in terms of goods, and hence of a capital that is lent. This will induce the lender to require a rate of interest that compensates him for this loss, whereas the borrower will be prepared to pay this higher rate: his productive activities will enable him to earn this additional charge. Hence it is to be expected that, once the rate of increase in prices has penetrated into the minds of the lenders and the borrowers, the rate of interest will be higher than normal during times of rising prices and lower during times of falling prices. If now, however, the correlation between interest rates and the price level itself is to be explained, it must be borne in mind that the rate of increase in prices precedes by one quarter of a period the price level itself. The correlation between interest rates and the rate of increase in prices must be assumed to be one with a lag and, in fact, of an average lag of about ten years. It would take ten years, then, before people would be aware of a long-run tendency of prices to rise or to fall. Is not this rather long? Five years may be accounted for immediately: in order to eliminate the ordinary cyclical movements we have to base our judgment on some moving average for about nine years, and it is only after five years that this can be known. Whether or not the remaining five-year lag can be understood psychologically is, to my mind, the point of doubt that arises here. ${ }^{6}$ Further investigations on this point would certainly be interesting.

An influence of a similar character is the one, already alluded to, exerted by the rate of increase in the interest rate itself. If there is a persisting tendency in one or the other direction, this means that there is an opposite movement in the prices of bonds which, in the case of a fall, means a capital loss to the owner, and in the case of a rise, a capital gain. Correspondingly, the demand for bonds - i.e. the supply of credit - will be lower than it would have been otherwise in periods of rising interest rates, and higher in times of falling rates. A tendency to a rise in interest rates will therefore bring about a tendency to a high level. Since interest

5. The Theory of Interest, New York, 1930.

6. I presented this interpretation in the Dutch article referred to above. 
rates, as we saw, move parallel to the general price level, this influence works parallel to the influence of a rising price level just discussed, and it will not be possible to separate these two forces.

Apart from these monetary long-run influences, what are the physical determinants of the interest rate? According to such theories as those of J. B. Clark and Von Böhm-Bawerk, and not in contradiction to our own scheme, it is the marginal productivity of capital: the factor behind the demand for credit. In the long run this marginal productivity will dpend on $(a)$ the change in relative scarcity of capital in comparison with the other agents of production, chiefly labor; and (b) an eventual common change in the efficiency of all the agents. A remarkable econometric contribution in this field is that made by Douglas and his collaborators. $^{7}$ Douglas fitted a homogeneous first degree production function

$$
P=c L^{\lambda} C^{1^{-\lambda}}
$$

to various sets of statistical material, where $P$ is the quantity of industrial output, $L$ the quantity of labor and $C$ the quantity of capital engaged and $c$ and $\lambda$ are constants. He found $\lambda$ to be about $2 / 3$ or $3 / 4$. From $(25,1)$ it is easily deduced that the marginal productivity of capital

$$
\frac{\partial P}{\partial C}=(1-\lambda)\left(\frac{L}{C}\right)^{\lambda}
$$

where $\frac{L}{C}$ is the inverted relative scarcity of capital relative to labor. Since $L$ and $C$ are, on conditions to be enumerated, to be considered as data, it would follow that equation $(25,2)$ tells us what determines, in the very long run, the course of interest rates. They should move inversely with the $2 / 3 \mathrm{~d}$ or $3 / 4$ th power of the relative scarcity of capital. Very roughly, the figures at our disposal secm to confirm this result. ${ }^{8}$ The conditions to be fulfilled are that, in the long run, the supply elasticities of labor and capital are equal to zero; that, in other words, the remuneration of these agent: does not change the proportion of the total supply available. Interesting investigations on these points have also been made by Douglas; ; the last word on these questions has not yet been spoken.

7. P. Douglas, The Theory of Wages, New York, 1934, and various later publications.

8. Cf. my article quoted above.

9. Loc. cit. 
26. Finally let us turn briefly to the problem of explaining the cyclical movements of interest rates. In sections 20-22 we have already given some attention to a possible theoretical set-up for such an explanation. The need for knowledge of the numerical values of the coefficients there introduced is evident: we demonstrated that the most conspicuous characteristics of cyclical movements may be explained only if these numerical values fulfill certain conditions. As far as I am aware, an investigation along exactly the lines indicated in sections $20-22$ is not possible, because of lack of data on gross flows of new short credits. Statistical data now at hand only permit of a stock or a net flow analysis, as far as short credits are concerned.

An attempt to determine the functional relationship between the interest rates and the demand for and supply of credits along such lines has been made in my investigation on business cycles in the United States referred to above. ${ }^{1} \mathrm{~A}$ few words may be added about the set-up chosen there in the light of the foregoing analysis. Three interest rates have been distinguished: two long-term rates, the yield on bonds $m_{L b}$ and the yield on shares $m_{L s}$ and one short term rate $m_{s}$. Accordingly, three demand and three supply functions have been determined. No more frequent figures than annual ones were available. For the supply and demand functions of short credits (being identical with demand and supply functions, respectively, for short "claims") a stock analysis was made; in the light of our discussion of this matter in section 19, we may hope this approaches a "gross flow" analysis, which we think is the appropriate way of analyzing this market. The correlations obtained are good, and do not therefore argue against this procedure. Of course, it would be interesting, however, to make further investigations in order to compare the results with those obtained by a gross and a net flow analysis. In addition, experiments with the use of smaller time units would be highly desirable.

The supply analysis of the long-term markets was also given the form of a stock analysis, i.e. the demand for bonds and shares was taken as a whole (demand for "new" as well as for "old" bonds and shares: the items ${ }^{1} S_{t}{ }^{\prime}+{ }^{D} E_{t}-{ }^{S} E_{t}$ in the market equation $(8,1)$ were combined), and it was tacitly assumed that during the reference period - i.e. one year - all bonds and shares were scrutinized by their holders. Here the same remarks apply as

1. Cf. Chapter IV. 
those made for the short-term market. The demand side of the long-term markets, however, was given the shape of a gross flow analysis: each year's issues were considered as a function of profits and interest rates then prevailing or some time before. This too seems legitimate, since the long period for which, from the side of the demand for these "credits" (or the supply of the corresponding "claims"), the contract is made makes it impossible each year to adapt their stock outstanding to the conditions of the market.

The procedure followed makes it difficult to trace the influence of the savings process on the rate of interest. It is assumed that family savings do not play any rôle in the supply of short credits. Hence they only enter into the picture at the supply side for long credits (or the demand side for long claims). Since here the stock analysis was followed, what had to come in was the annual figure of the cumulation of anterior savings. This is a series of figures showing mainly a trend and only a faint cyclical component. Its influence, therefore, cannot very well be separated from other influences showing mainly a trend. One further factor entering into this demand function for long claims and showing mainly a trend movement is the quantity of bonds and of shares present at any moment, and since this also is a cumulation, the separation of the influences of these two factors by means of correlation analysis is practically impossible.

Among the rather scarce econometric investigations in the field of credit markets mention should also be made of the studies by A. J. Brown. ${ }^{2}$ Here again a stock analysis is chosen.

\section{J. Tinbergen.}

Netherlands School of Economics

ROTTERDAM

2. The Liquidity Preference Schedules of the London Clearing Banks, Oxford Economic Papers 1 (1938), p. 49. 